\title{
Gastric Ganglioneuroblastoma in an Elder Man: A Case Report and Literature Review
}

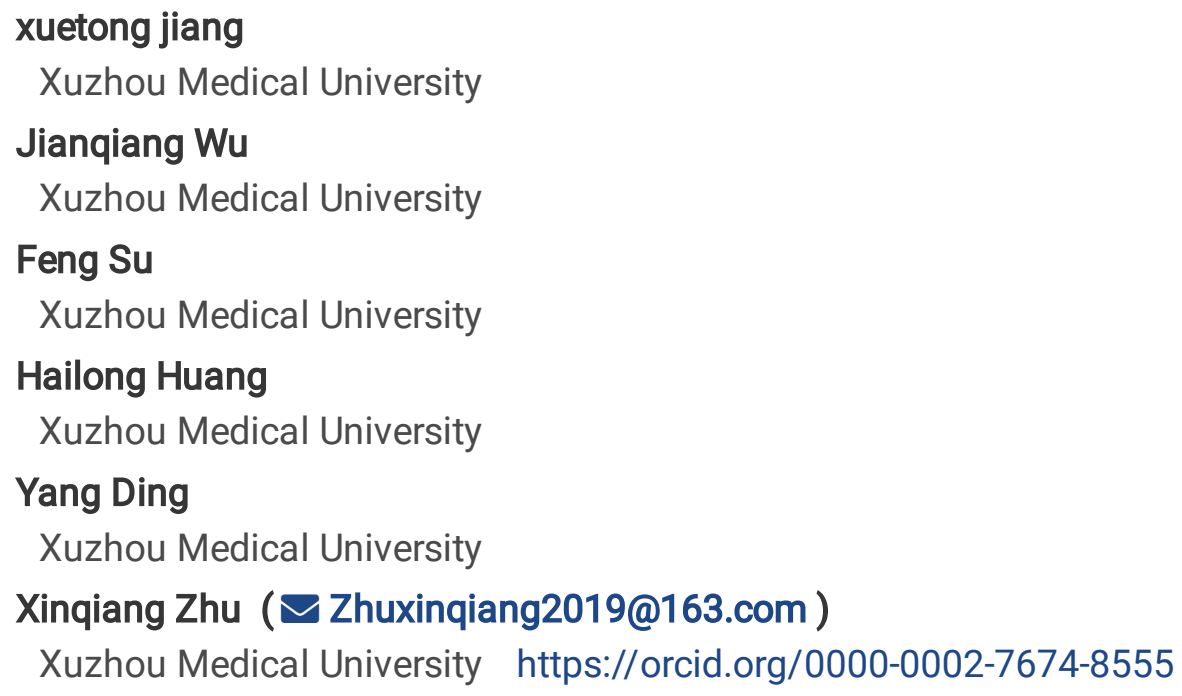

\section{Case report}

Keywords: Gastric, Ganglioneuroblastoma, laparoscopic surgery

Posted Date: February 5th, 2021

DOI: https://doi.org/10.21203/rs.3.rs-191276/v1

License: (c) (i) This work is licensed under a Creative Commons Attribution 4.0 International License. Read Full License 


\section{Abstract}

Background: GNB is a moderate tumor of sympathetic origin, which is considered a disease of children with the majority of cases less than five years old and it rarely occurs in adults. There are no treatment guidelines for adults GNB. Here, we reported a rare case of adult gastric GNB, and was resected completely by laparoscopic approach.

Case presentation:A 73-year-old man presented with dull pain in the upper abdomen along with abdominal distension for one month. Gastroscopy examination revealed chronic gastritis and submucosal tumor of gastric antrum. Endoscopic ultrasonography showed a hypoechoic mass in gastric antrum arising from the muscularis propria. Combined with the characteristics of gastroscope and ultrasound, the mass was suspected as gastrointestinal stromal tumor. Abdomen CT scan of revealed irregular soft tissue mass in gastric antrum with heterogeneous enhancement in arterial phase, and gastric cancer was suspected. The patient was addressed to the department of gastrointestinal surgery. The mass was completely resected in laparoscopic surgery. Histopathology reported that the mass contained differentiation neuroblasts, mature ganglion cells and ganglioneuromatisis component. Immunohistochemical staining revealed tumor cells were immunoreactive for CD56, Syn, S100, while negative for CK, CD117, DOG-1, CgA. The pathological diagnosis was GNBi and the patient was staged as stage I. The patient received no adjuvant chemotherapy or radiotherapy.Until his one-year follow-up, the patient was doing well and without any signs of recurrence.

Conclusion:Although the rarity of gastric GNB as a primary site of origin, it should be considered in the differential diagnosis of gastric masses in adult. Radical surgery is sufficient for the treatment of GNBi and long-term follow-up should be performed.

\section{Background}

Neuroblastic tumor is a solid malignant tumor with origin from the chain of sympathetic nerves system and primitive migration neuroectoderm cells or pluripotent sympathetic cells arising from neural crest of adrenal medulla, which can be divided into four categories by histological features in International Neuroblastoma Pathology Classification: neuroblastoma (NB) , ganglioneuroblastoma nodular (GNBn), ganglioneuroblastoma intermixed (GNBi) and ganglioneuroma (GN)[1].

ganglioneuroblastoma(GNB) is a moderate tumor, which composed two histological features of neuroblastoma and mature ganglioneuroma. GNB is most common malignancy of early childhood, especially in less than five years old, about $60 \%$ of the cases were diagnosed in first two years , $90 \%$ in five years old, and rare after ten years old[2-4]. GNB is exceedingly rare in adult with incidence of about one case per 10 million adults per year $[5,6]$.

As far as we know, there is no reported case of GNB in china arising from the gastric in adult. Here, we present a rare case of a 73-year-old man with gastric GNB, and was resected completely by laparoscopic approach.

\section{Case Presentation}

A 73-year-old man presented with dull pain in the upper abdomen along with abdominal distension for one month without any reasons, the pain can be aggravated after eating and catching a cold. Beside these, the patient also compliant with intermittent acid reflux. He did not have the symptoms of belching, nausea, vomiting, hematochezia, diarrhea and fever. He had a fifty years history of smoking and drinking with twenty cigarettes and $100 \mathrm{~g}$ alcohol per day, but he has given up smoking and drinking for three years. He denied hypertension, diabetes, heart 
disease, hepatitis B, tuberculosis and the history of surgery. Clinical physical examination show tenderness of upper abdomen without rebound tenderness, and no palpable abdominal mass. His blood pressure was 140/80 mmHg, hart rate 79 beats/min, SPO2 99\%(room air ), and the body mass index(BMI) $22.85 \mathrm{~kg} / \mathrm{m}^{2}$.

Before admitting our hospital, gastroscopy examination was conducted in local hospital, revealing chronic gastritis and submucosal tumor of gastric antrum, and the examination of endoscopic ultrasound was recommended.

The patient was admitted into the department of gastroenterology and a gastroscopy was performed which showed a submucosal bulge mass in the anterior wall of the gastric antrum with smooth surface, wide base, hard texture and poor mobility. A subsequent endoscopic ultrasonography showed a hypoechoic mass in gastric antrum arising from the muscularis propria was found in size of $3 \times 4$ centimeter $(\mathrm{cm}) \otimes F i g u r e 1 \mathrm{a} \bigotimes \mathrm{b} \bigotimes$. Combined with the characteristics of gastroscope andultrasound, the submucosal mass was suspected as gastrointestinal stromal tumor. A computed tomography (CT) scan of abdomen revealed irregular soft tissue mass in gastric antrum measuring $29 \times 47 \times 49 \mathrm{~mm}$ in dimensions and there was no clear boundary between the lesion and the neck of the pancreas. Dynamic analysis revealed a mild heterogeneous enhancement in arterial phase. There was no suspicious lymphadenopathy around the stomach. The gastric antrum lesions was diagnosed as gastric cancer with stage of T3囚Figure $1 \mathrm{c} \rrbracket \mathrm{d} \rrbracket$.

Colonoscopy examination showed no abnormality in the colorectal mucosa. Abdominal ultrasound showed a strong echogenic mass measuring $8 \times 5$ millimeter in the left kidney and was considered as renal calculus.

After multi-disciplinary team discussion, considering endoscopic features and the size, the mass was excluded as gastric cancer, but cannot be treated by endoscopic submucosal dissection or endoscopic mucosal resection and a surgery resection was recommended. The patient was addressed to the department of gastrointestinal surgery for surgical resection.

Preoperative evaluation revealed normal lung function and heart function with left ventricular ejection fraction of $60 \%$. The electrocardiogram recorded normal sinus rhythm. Results of the complete blood count, liver and kidney function, plasma levels of electrolytes, coagulation function test, and urinalysis were normal. The tumor markers including serum carcinoembryonic antigen (CEA), alpha fetal protein (AFP), carbohydrate antigen 19-9凶CA19-9凶, cancer antigen $50 \varangle \mathrm{CA50}$, cancer antigen $242 \varangle \mathrm{CA} 242 \rrbracket$ and cancer antigen $724 \varangle \mathrm{CA} 724 \rrbracket$ were all normal. The chest CT revealed chronic bronchitis, emphysema and bullae.

After obtaining the informed consent of the patient and family laparoscopic surgery was performed under general anesthesia. During laparoscopic exploration, a well-defined mass located in gastric antrum anterior wall near lesser curvature was confirmed with size of $4 \mathrm{~cm}$. The mass was outside the cavity growth and had clear boundary with the pancreas. No suspicious lymphadenopathy around stomach and other lesions were found. The mass as completely resected with $1 \mathrm{~cm}$ margins using a $60 \mathrm{~mm}$ laparoscopic linear cutting stapler, and without pylorostenosis after resection.

Postoperative histopathology reported that the mass contained differentiation neuroblasts, mature ganglion cells and ganglioneuromatisis component. In the neuroblastic area, small oval cells arranged in sheets and nests entangled in background of neurofibrillary stromal (Figure 2b). Besids that, mature hyperchromatic ganglion cells also be found.(Figure 2a). Immunohistochemical staining revealed tumor cells were immunoreactive for Syn (+++) CD56(+++), S100(+++) (Figure 2c,d,e), while the tumor cells were negative for CgA(Figure 2f) ,CK, CD117, D0G-1. The mitosis-karyorrhexis index $(\mathrm{MKI})$ was $<2 \%$. These findings were consistent with intermixed 
ganglioneuroblastom. Supplementary test showing neuron-specific enolase (NSE) was $3.175 \mathrm{ng} / \mathrm{mL}$ (normal < $10 \mathrm{ng} / \mathrm{mL}$ ). Unfortunately, the patient refused to undergo further genetic testing, and we were unable to assess the status of MYCN. According to the criteria of international neuroblastoma staging system (INSS)[7], the patient was staged as stage $\mathrm{I}$.

The patient was discharged from hospital on the eighth day after surgery. The patient received no adjuvant chemotherapy or radiotherapy based on the favorable histology. The patient was followed every three months. Tests like abdominal CT, complete blood count, urinary catecholamine analysis were conducted. I-131 Metaiodobenzylguanidine (I-131 MIBG) scan was performed in the 6th month and there was no evidence of recurrence and metastasis at the one-year follow-up.

\section{Discussion And Conclusion}

GNB is a pediatric tumor and extremely rare in adults. Less than 50 cases of GNB have been reported in adults .GNB can occur any site of from the base of the skull to the pelvis, most frequently in adrenal gland(35\%), retroperitoneum gangia $(30 \%-35 \%)$, and posterior mediastinum (20\%), pelvis $₫ 2-3 \% \bigotimes[8]$,but also located in same rare site like brain,cervical region[9].

Only a few cases have been reported gastric GNB in english literature. Sandoval reported a case of multifocal ganglioneuroblastomas, who had a right cervical tumor, a left posterior mediastinal. tumor, bilateral adrenal tumors, and bony and bone marrow metastases. the gastric involvement was only detected by meticulous exploration during laparotomy[10]. Here, we describe a rare case of gastric GNB resected completely by laparoscopy in a 73year-old male elder.

The international neuroblastoma pathology classification defined the histological features and proposed four tumor categories:NB , GNBn, GNBi and GN. The four tumor categories are divided in two distinct prognostic groups: favorable histology and unfavorable histology $[1,11] \rrbracket$ see table $1 \rrbracket$.The tumor type of our case was GNBi , favorable histology.

In 1993, the international classification INSS published a surgicopathologic staging system used for the staging of the disease[7] (see table 2). This stage system has some limitation, like patients who are yet to have surgery. The behavior of neuroblastic tumor can be affected by many factors. Most important prognostic factors are age at the diagnosis,primary site of tumor,histology,disease stage, status of NMYC, chromosome 11q status and DNA ploidy[12-15].These factors were incorporated into the International Neuroblastoma Risk Group (INRG) classification system to establish a consensus for pretreatment classification (see table 3). Neuroblastoma is classified into four categories: very low-risk, low-risk, intermediate-risk, or high-risk.

The clinical manifestations of GNB are different. The most common symptoms are abdominal mass, abdominal pain, abdominal swelling , and effect of metastasis[6, 16]. Vomiting, diarrhea and poor feeding were also identified in a small proportion of patients.[17]This case presented upper abdomen pain along with abdominal swelling.

$\mathrm{CT}$ and magnetic resonance imaging (MRI) with contrast can provide valuable diagnosis information for GNB. CT can be used to find the primary site of the tumor and approximately $50 \%$ of GNBs have calcification[4]. The features of GNBs on enhanced CT can ranging from well marginated masses with homogeneous enhancement to irregular, cystic, hemorrhagic, or locally invasive masses[4, 18]. On MRI, GNB is typically homogeneous with enhancement and appears high signal intensity on T2-weighted images and low signal intensity on T1-weighted images[19]. In 
our case, CT scan revealed irregular soft tissue mass in gastric antrum with unclear boundary, and dynamic analysis revealed a mild heterogeneous enhancement, without calcification.

The final diagnosis depends on histopathological examination and immunohistochemical staining. GNB are composed of both mature ganglion cells and neuroblasts. For immunohistochemical staining, NSE, Syn, CgA, S100, CD30 are often positive in tumor tissues[20,21]. In our case, the histopathological and immunohistochemical features were line with GNBi. The tumor was classified as Stage 1 according to INSS.

There are no treatment guidelines for adults GNB. The treatment principle is derived from pediatric experience. The therapeutic strategy includes surgery, chemotherapy, and radiotherapy.The radical surgery is the best and main treatment available for GNBs[7, 22-24]. If the tumor is not completely removed or in metastatic stage, chemotherapy should be performed[25].Patients with NMYC amplification or deletion of the short arm of chromosome 1 are related to poor prognosis $[13,15]$. Surgery and postoperative chemotherapy can be treatment choice for these patients and chemotherapy schedules with higher dose intensity are recommended. Chemotherapy regimens utilized include include cisplatin, etoposide, vincristine, cyclophosphamide, and doxorubicin[26]. Recenlty, topotecan and temozolomide have been used in patients with relapsed disease and demonstrated a significant antitumor activity $[27,28]$. In inoperable, unresectable and metastatic cases, radiotherapy should be considered for symptom palliation associated with metastatic masses[29]. Boris Decarolis et al[30] reported that GNBi have excellent prognosis and cytotoxic treatment has no substantial effect on it. Surgery alone is enough for the treatment of GNBi and does not need to be radical if tumor residuals were smaller than $2 \mathrm{~cm}$.

Disease recurrence has been found to occur mostly in the first two years after surgery. Therefore, the patients should be followed every 3 months for the first and second years, then every 6 months. Attention to the symptoms and careful physical examination are fundamental, Bolzacchini et al[31] suggested that complete blood count, urinary catecholamine analysis, and imaging of the site of the primary tumor should be performed at every examination. I-131MIBG scintigraphyan can help to detect bone metastasis. It is recommended to perform I131 MIBG scintigraphy every 6 months in the first and second year.

In our case, the patient was in stage 1 disease of GNBi, could receive surgery treatment without adjuvant chemotherapy or radiotherapy. There was no sign of recurrence or metastasis in one year after operation. However, long-term follow-up is needed.

In conclusion, we have presented a case of a 73-year-old man with gastric $\mathrm{GNBi}$, and was resected completely by laparoscopic approach. Our report suggested that although the rarity of gastric GNB as a primary site of origin, it should be considered in the differential diagnosis of gastric masses in adult. Radical surgery is sufficient for the treatment of GNBi and long-term follow-up should be performed.

\section{Abbreviations}

NB neuroblastoma $₫$ GNBn ganglioneuroblastoma nodular $\rrbracket$ GNBi ganglioneuroblastoma intermixed $₫ \mathrm{GN}$

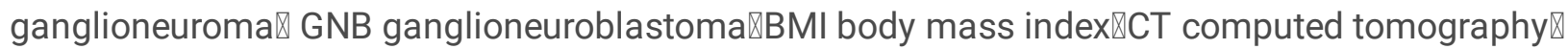

CEA carcinoembryonic antigen $₫$ AFP alpha fetal protein $\nabla$ CA19-9 carbohydrate antigen 19-9凶 CA50 cancer antigen 50『CA242 cancer antigen 242『 CA724 cancer antigen 724 『NSE neuron-specific enolase 『INSS international

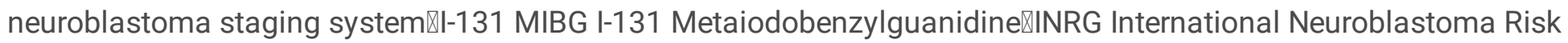
Group $\triangle \mathrm{MRI}$ magnetic resonance imaging. 


\section{Declarations}

\section{Acknowledgements}

Not applicable

\section{Authors' contributions}

$X$ Jiang performed preoperative investigation and drafted the manuscript. $J$ Wu contributed to the paper design and coordination, F Su,H Huang performed preoperative investigation.Y Ding conducted the pathological examination and immunostaining. $X$ Zhu performed surgery and revised the manuscript for important intellectual content, and provided the final approval for the version to be submitted for publication.All authors have read and approved the final manuscript.

\section{Funding}

None of the authors have any sources of funding to disclose.

\section{Availability of data and materials}

All data generated or analyzed during this study are included in this published article.

\section{Ethics approval and consent to participate}

All procedures used in this research were approved by the Ethics Committee

of the the affiliated Suqian Hospital of Xuzhou Medical University

\section{Consent for publication}

Written informed consent was obtained from the patient's family for the

publication of this case report and any accompanying images. A copy of the

written consent form is available for review by the Editor-in-Chief of this

journal.

\section{Competing interests}

The authors have no competing interests to declare.

\section{Author details}

${ }^{1}$ Department of Gastrointestinal Surgery, the Affiliated Suqian Hospital of Xuzhou Medical University, No.138 Huanghe South Road, 223800, China

${ }^{2}$ Department of Digestion, the Affiliated Suqian Hospital of Xuzhou Medical University, No.138 Huanghe South Road, Suqian 223800, China 
${ }^{3}$ Department of Pathology, the Affiliated Suqian Hospital of Xuzhou Medical University, No.138 Huanghe South Road, Suqian 223800, China

\section{References}

1. Shimada H, Ambros IM, Dehner LP, Hata J, Joshi VV, Roald B, Stram DO, Gerbing RB, Lukens JN, Matthay KK, Castleberry RP: The International Neuroblastoma Pathology Classification (the Shimada system). Cancer-Am Cancer Soc 1999, 86:364-372.

2. Lam AK: Update on Adrenal Tumours in 2017 World Health Organization (WHO) of Endocrine Tumours. Endocr Pathol 2017, 28:213-227.

3. Decarolis B, Simon T, Krug B, Leuschner I, Vokuhl C, Kaatsch P, von Schweinitz D, Klingebiel T, Mueller I, Schweigerer $\mathrm{L}$, et al: Treatment and outcome of Ganglioneuroma and Ganglioneuroblastoma intermixed. Bmc Cancer 2016, 16:542.

4. Lonergan GJ, Schwab CM, Suarez ES, Carlson CL: Neuroblastoma, ganglioneuroblastoma, and ganglioneuroma: radiologic-pathologic correlation. Radiographics 2002, 22:911-934.

5. Siegel R, Naishadham D, Jemal A: Cancer statistics, 2012. CA Cancer J Clin 2012, 62:10-29.

6. Rogowitz E, Babiker HM, Kanaan M, Millius RA, Ringenberg QS, Bishop M: Neuroblastoma of the elderly, an oncologist's nightmare: case presentation, literature review and SEER database analysis. Exp Hematol Oncol 2014, 3:20.

7. Brodeur GM, Pritchard J, Berthold F, Carlsen NL, Castel V, Castelberry RP, De Bernardi B, Evans AE, Favrot M, Hedborg F, Et A: Revisions of the international criteria for neuroblastoma diagnosis, staging, and response to treatment. J Clin Oncol 1993, 11:1466-1477.

8. Ramaswamy B, Bhandarkar AM, Menon SS, Agarwal AC, Nair SS: Ganglioneuroblastoma of Skull Base. J Clin Diagn Res 2015, 9:D1-D3.

9. Lu D, Liu J, Chen Y, Chen F, Yang H: Primary cervical ganglioneuroblastoma: A case report. Medicine (Baltimore) 2018, 97:e90.

10. Sandoval C, Oiseth S, Slim M, Tugal O, Ozkaynak MF, Brudnicki A, Beneck D, Bostwick H, Jayabose S: Gastric ganglioneuroblastoma: a rare finding in an infant with multifocal ganglioneuroblastoma. J Pediatr Hematol Oncol 1996, 18:409-412.

11. Peuchmaur M, D'Amore ES, Joshi VV, Hata J, Roald B, Dehner LP, Gerbing RB, Stram DO, Lukens JN, Matthay $\mathrm{KK}$, Shimada H: Revision of the International Neuroblastoma Pathology Classification: confirmation of favorable and unfavorable prognostic subsets in ganglioneuroblastoma, nodular. Cancer-Am Cancer Soc 2003, 98:2274-2281.

12. Cotterill SJ, Pearson AD, Pritchard J, Foot AB, Roald B, Kohler JA, Imeson J: Clinical prognostic factors in 1277 patients with neuroblastoma: results of The European Neuroblastoma Study Group 'Survey' 1982-1992. Eur J Cancer 2000, 36:901-908.

13. Spitz R, Hero B, Simon T, Berthold F: Loss in chromosome 11q identifies tumors with increased risk for metastatic relapses in localized and 4S neuroblastoma. Clin Cancer Res 2006, 12:3368-3373.

14. Goto S, Umehara S, Gerbing RB, Stram DO, Brodeur GM, Seeger RC, Lukens JN, Matthay KK, Shimada H: Histopathology (International Neuroblastoma Pathology Classification) and MYCN status in patients with peripheral neuroblastic tumors: a report from the Children's Cancer Group. Cancer-Am Cancer Soc 2001, 92:2699-2708. 
15. Bagatell R, Beck-Popovic M, London WB, Zhang Y, Pearson AD, Matthay KK, Monclair T, Ambros PF, Cohn SL: Significance of MYCN amplification in international neuroblastoma staging system stage 1 and 2 neuroblastoma: a report from the International Neuroblastoma Risk Group database. J Clin Oncol 2009, 27:365-370.

16. Podda MG, Luksch R, Polastri D, Gandola L, Piva L, Collini P, Cefalo G, Terenziani M, Ferrari A, Casanova M, et al: Neuroblastoma in patients over 12 years old: a 20-year experience at the Istituto Nazionale Tumori of Milan. Tumori 2010, 96:684-689.

17. He WG, Yan Y, Tang W, Cai R, Ren G: Clinical and biological features of neuroblastic tumors: A comparison of neuroblastoma and ganglioneuroblastoma. Oncotarget 2017, 8:37730-37739.

18. Pavlus JD, Carter BW, Tolley MD, Keung ES, Khorashadi L, Lichtenberger JR: Imaging of Thoracic Neurogenic Tumors. AJR Am J Roentgenol 2016, 207:552-561.

19. Rao AA, Naheedy JH, Chen JY, Robbins SL, Ramkumar HL: A clinical update and radiologic review of pediatric orbital and ocular tumors. J Oncol 2013, 2013:975908.

20. Daneshbod Y, Khojasteh HN, Zamiri B, Daneshbod K: Metastatic ganglioneuroblastoma in head and neck diagnosed by fine needle aspiration: a case report. Acta Cytol 2007, 51:429-433.

21. Salmi D, Patel C, Imashuku S, Shimada H, Satake N: Neuroblastoma of unknown primary site with periorbital bone metastasis in a child. Pediatr Blood Cancer 2010, 55:361-363.

22. Decarolis B, Simon T, Krug B, Leuschner I, Vokuhl C, Kaatsch P, von Schweinitz D, Klingebiel T, Mueller I, Schweigerer L, et al: Treatment and outcome of Ganglioneuroma and Ganglioneuroblastoma intermixed. Bmc Cancer 2016, 16:542.

23. Huang MD, Hsu LS, Chuang HC, Lin WY, Lin WH, Yen CW, Chen ML: Adult renal neuroblastoma: A case report and literature review. Medicine (Baltimore) 2018, 97:e345.

24. Cohn SL, Pearson AD, London WB, Monclair T, Ambros PF, Brodeur GM, Faldum A, Hero B, lehara T, Machin D, et al: The International Neuroblastoma Risk Group (INRG) classification system: an INRG Task Force report. J Clin Oncol 2009, 27:289-297.

25. Irwin MS, Park JR: Neuroblastoma: paradigm for precision medicine. Pediatr Clin North Am 2015, 62:225-256.

26. Kushner BH, LaQuaglia MP, Bonilla MA, Lindsley K, Rosenfield N, Yeh S, Eddy J, Gerald WL, Heller G, Cheung NK: Highly effective induction therapy for stage 4 neuroblastoma in children over 1 year of age. J Clin Oncol 1994, 12:2607-2613.

27. Garaventa A, Luksch R, Biasotti S, Severi G, Pizzitola MR, Viscardi E, Prete A, Mastrangelo S, Podda M, Haupt R, De Bernardi B: A phase II study of topotecan with vincristine and doxorubicin in children with recurrent/refractory neuroblastoma. Cancer-Am Cancer Soc 2003, 98:2488-2494.

28. Rubie H, Chisholm J, Defachelles AS, Morland B, Munzer C, Valteau-Couanet D, Mosseri V, Bergeron C, Weston C, Coze C, et al: Phase II study of temozolomide in relapsed or refractory high-risk neuroblastoma: a joint Societe Francaise des Cancers de l'Enfant and United Kingdom Children Cancer Study Group-New Agents Group Study. J Clin Oncol 2006, 24:5259-5264.

29. Benderli CY, Aytekin A, Sarigoz T: Role of radiotherapy in adult ganglioneuroblastoma and ganglioneuroma. $J$ Buon 2016, 21:750.

30. Decarolis B, Simon T, Krug B, Leuschner I, Vokuhl C, Kaatsch P, von Schweinitz D, Klingebiel T, Mueller I, Schweigerer $\mathrm{L}$, et al: Treatment and outcome of Ganglioneuroma and Ganglioneuroblastoma intermixed. Bmc Cancer 2016, 16:542. 
31. Bolzacchini E, Martinelli B, Pinotti G: Adult onset of ganglioneuroblastoma of the adrenal gland: case report and review of the literature. Surg Case Rep 2015, 1:79.

\section{Tables}

Table 1 International Neuroblastoma Pathology Classification

\begin{tabular}{|ll|}
\hline Category and subtype & Pathology classification \\
\hline NB & FH and UH subgroups, based on the combination of age, grade of \\
(Schwannian stroma-poor) & \\
\hline Undifferentiated & \\
Poorly differentiated & \\
\hline Differentiating & FH \\
GNBi & \\
( schwannian stroma-rich) & \\
GN & $F H$ \\
(schwannian stroma-dominant) \\
$\begin{array}{l}\text { Maturing } \\
\text { Mature }\end{array}$ \\
$\begin{array}{l}\text { GNBn } \\
\text { (schwannianstroma-rich/stroma- } \\
\text { dominant and stroma-poor) }\end{array}$ \\
\hline
\end{tabular}

FH favorable histology, UH unfavorable histology, MKI mitosis-karyorrhexis index

aTumors in this category were classified into an unfavorable histology group according to the International Neuroblastoma Pathology Classification

Table 2 The International Neuroblastoma Staging System (INSS) 


\begin{tabular}{|c|c|}
\hline $\begin{array}{l}\text { Stage/Prognostic } \\
\text { group }\end{array}$ & Description \\
\hline Stage 1 & $\begin{array}{l}\text { Localized tumor with complete gross excision, with or without microscopic residual } \\
\text { disease; representative ipsilateral lymph nodes negative for tumor microscopically (i.e., } \\
\text { nodes attached to and removed with the primary tumor may be positive). }\end{array}$ \\
\hline Stage $2 \mathrm{~A}$ & $\begin{array}{l}\text { Localized tumor with incomplete gross excision; representative ipsilateral non-adherent } \\
\text { lymph nodes negative for tumor microscopically. }\end{array}$ \\
\hline Stage 2B & $\begin{array}{l}\text { Localized tumor with or without complete gross excision, with ipsilateral non-adherent } \\
\text { lymph nodes positive for tumor. Enlarged contralateral lymph nodes must be negative } \\
\text { microscopically }\end{array}$ \\
\hline Stage 3 & $\begin{array}{l}\text { Unresectable unilateral tumor infiltrating across the midline, with or without regional lymph } \\
\text { node involvement; or localized unilateral tumor with contralateral regional lymph node } \\
\text { involvement; or midline tumor with bilateral extension by infiltration (unresectable) or by } \\
\text { lymph node involvement. The midline is defined as the vertebral column. Tumors } \\
\text { originating on one side and crossing the midline must infiltrate to or beyond the opposite } \\
\text { side of the vertebral column. }\end{array}$ \\
\hline Stage 4 & $\begin{array}{l}\text { Any primary tumor with dissemination to } \\
\text { distant lymph nodes, bone, bone marrow, } \\
\text { liver, skin, and/or other organs, except as } \\
\text { defined for } \\
\text { stage 4S. }\end{array}$ \\
\hline Stage 4S & $\begin{array}{l}\text { Localized primary tumor, as defined for stage } 1,2 \mathrm{~A} \text {, or } 2 \mathrm{~B} \text {, with dissemination limited to } \\
\text { skin, liver,and/or bone marrow (by definition limited to infants younger than } 12 \text { months). } \\
\text { Marrow involvement should be minimal (i.e., }<10 \% \text { of total nucleated cells identified as } \\
\text { malignant by bone biopsy or by bone marrow aspirate). More extensive bone marrow } \\
\text { involvement would be considered stage } 4 \text { disease. The results of the mIBG scan, if } \\
\text { performed, should be negative for disease in the bone marrow. }\end{array}$ \\
\hline
\end{tabular}

mIBG metaiodobenzylguanidine

Table 3 International Neuroblastoma Risk Group Consensus Pretreatment Classification Scheme 


\begin{tabular}{|c|c|c|c|c|c|c|c|}
\hline INRG stage & $\begin{array}{l}\text { Age } \\
\text { (months) }\end{array}$ & $\begin{array}{l}\text { INPC } \\
\text { group }\end{array}$ & $\begin{array}{l}\text { Grade of } \\
\text { differentiation }\end{array}$ & $\begin{array}{l}\text { MY } \\
\text { CN }\end{array}$ & $\begin{array}{l}11 \mathrm{q} \\
\text { aberration }\end{array}$ & ploidy & $\begin{array}{l}\text { Pretreatment } \\
\text { risk group }\end{array}$ \\
\hline L1/L2 & & $\begin{array}{l}\text { GN } \\
\text { maturing; } \\
\text { GNB } \\
\text { intermixed }\end{array}$ & & & & & Very low \\
\hline \multirow{2}{*}{$\begin{array}{l}\text { L1 } \\
\text { Localized } \\
\text { tumor } \\
\text { confined to } \\
\text { one body } \\
\text { compartment } \\
\text { and with } \\
\text { absence of } \\
\text { image-defined } \\
\text { risk factors }\end{array}$} & & $\begin{array}{l}\text { Any, } \\
\text { except GN } \\
\text { maturing } \\
\text { or GNB } \\
\text { intermixed }\end{array}$ & & NA & & & Very low \\
\hline & & & & AM & & & High \\
\hline \multirow{6}{*}{$\begin{array}{l}\text { L2 } \\
\text { Locoregional } \\
\text { tumor with } \\
\text { presence of } \\
\text { one or more } \\
\text { image-defined } \\
\text { risk factor }\end{array}$} & $\otimes 18$ & $\begin{array}{l}\text { Any, } \\
\text { except GN }\end{array}$ & Differentiating & NA & NO & & Low \\
\hline & & $\begin{array}{l}\text { maturing } \\
\text { or GNB } \\
\text { intermixed }\end{array}$ & & & Yes & & Intermediate \\
\hline & & & & & NO & & Low \\
\hline & & & & & Yes & & \\
\hline & $\geq 18$ & $\begin{array}{l}\text { GNB } \\
\text { nodular; }\end{array}$ & $\begin{array}{l}\text { Poorly } \\
\text { differentiated or } \\
\text { undifferentiated }\end{array}$ & NA & & & Intermediate \\
\hline & & TND & & AM & & & High \\
\hline \multirow{5}{*}{$\begin{array}{l}\text { M } \\
\text { Distant } \\
\text { metastatic } \\
\text { disease(except } \\
\text { ) }\end{array}$} & $\nabla 18$ & & & NA & & Hyperploid & Low \\
\hline & $\otimes 12$ & & & NA & & Diploid & Intermediate \\
\hline & $12-18$ & & & NA & & Diploid & Intermediate \\
\hline & $\otimes 18$ & & & AM & & & High \\
\hline & $\geq 18$ & & & & & & High \\
\hline \multirow{3}{*}{$\begin{array}{l}\text { MS } \\
\text { Metastatic } \\
\text { disease } \\
\text { confined to } \\
\text { skin, liver, } \\
\text { and/or bone } \\
\text { marrow in }\end{array}$} & & & & NA & NO & & Very low \\
\hline & & & & & Yes & & High \\
\hline & & & & AM & & & High \\
\hline
\end{tabular}

Page 11/13 
INRG: International Neuroblastoma Risk Group; INPC : International Neuroblastoma Pathology Classification; NA :not amplified ; AM : amplified

\section{Figures}
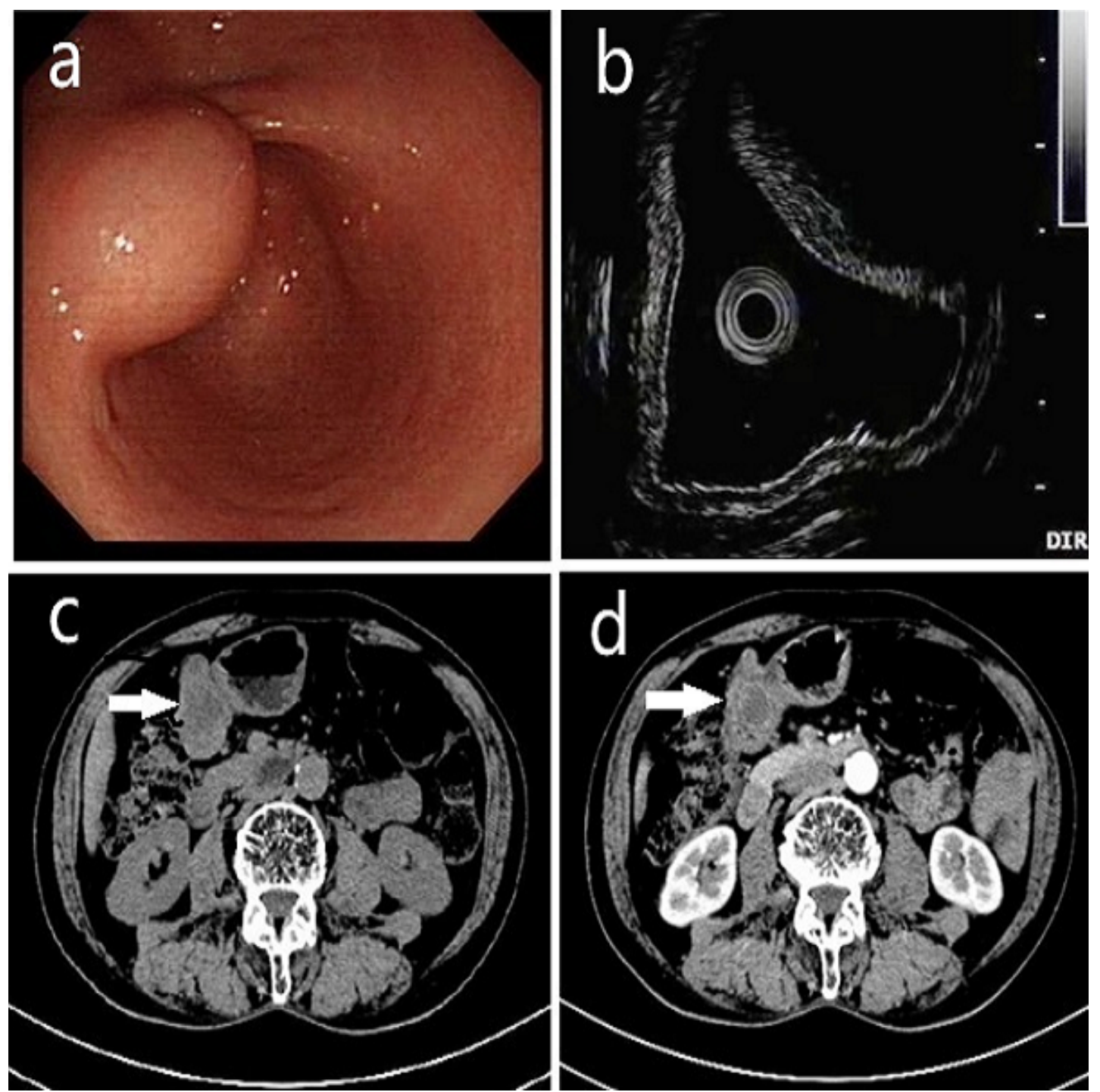

Figure 1

Representative images of the endoscopic ultrasonography and CT. a the mass in gastric antrum in size of $3 \times 4$ centimeter. $b$ the hypoechoic mass arising from the muscularis propria. $c$ irregular soft tissue mass in gastric antrum measuring $29 \times 47 \times 49 \mathrm{~mm}$ in dimensions.d a mild heterogeneous enhancement in arterial phase. 

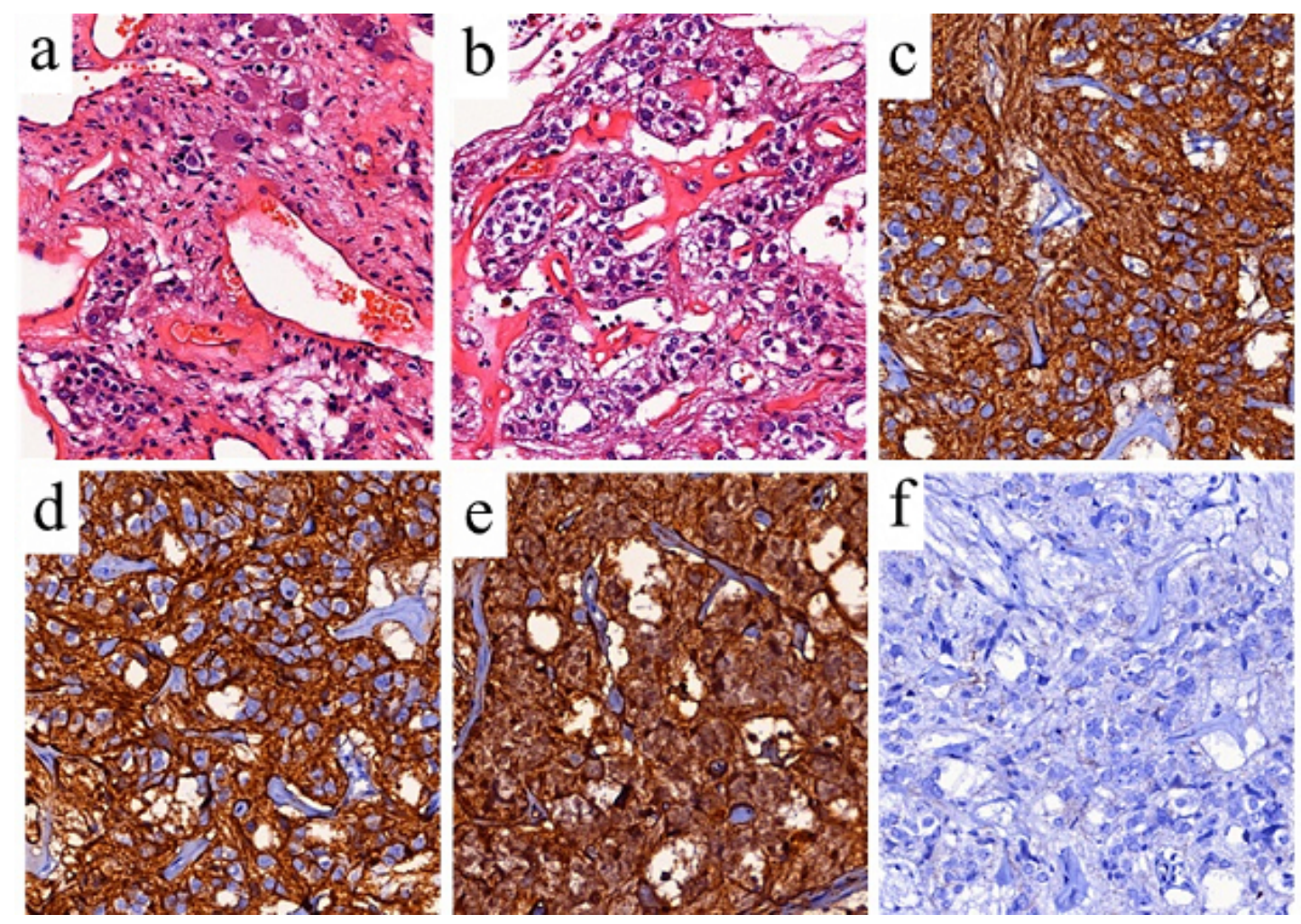

Figure 2

The pathological findings of the resected mass indicated mature hyperchromatic ganglion cells (a) and ganglioneuromatisis component, In the neuroblastic area, small oval cells arranged in sheets and nests entangled in background of neurofibrillary stromal(b). Hematoxylin and eosin (H\&E) stain. $\times 200$. Immunohistochemical

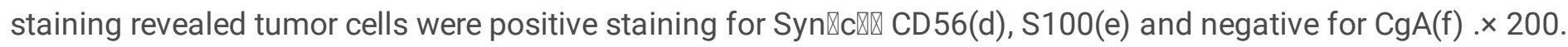

